\title{
Bridging the Achievement Gap for Students: A Blueprint for Success ${ }^{1}$
}

\author{
Kirk Gavin, Rose Campbell, Seward Hamilton \\ Florida Agricultural and Mechanical University, Tallahassee, USA
}

\begin{abstract}
The purpose of this research is to identify and examine the achievement gaps between students. Over the past thirty years, emphasis has been placed on achievement levels of students in this country. State test results, SAT Scores, ACT scores and other assessment instruments have been used to determine performance standards and test results for students. Data analyzed for White students compared to African American and Hispanic students have provided critical information in identifying academic progress and skill deficits for all students. This article will highlight some of the achievement gaps which exit among White, African American and Hispanic Students. Recommendations will also be emphasized to help improve student achievement levels in an effort to close the achievement gap.
\end{abstract}

Keywords: student achievement, achievement gap, comparative achievement levels

\section{Introduction}

Can we close the Achievement gap for students in the United States? This is a crucial question that must be asked by everyone who is concerned about the academic performance of all students. For several decades there has been a major focus on the academic success of African American and Hispanic students and their performance on standardized assessments when compared to their White counterparts. Several initiatives have been implemented to address this alarming deficiency in students who did not show mastery of various skill levels in reading and in mathematics.

\section{Visionary Leadership}

Leadership as indicated by the Wallace Foundation is for insuring that every student will receive the best education in America to help them become successful. Good principals are usually visionary and instructional leaders who are able to transform poor schools into productive learning environments by taking charge, making good decisions, demonstrating their leadership ability by inspiring and motivating teachers, students, parents and staff. This is the type of principal who can also think out of the box and is able to address especially the needs of all students in the school. Most principals take into consideration the cultural diversity of the school's population

\footnotetext{
1 This article will highlight some of the achievement gaps which exit among White, African American, and Hispanic Students Kirk Gavin, Ed.D., Director for Teacher Induction Program, Florida Agricultural and Mechanical University. Rose J. Campbell, Ed.D., Faculty Administrator, Florida Agricultural and Mechanical University. Seward E. Hamilton, Ph.D., Associate Professor, Florida Agricultural and Mechanical University.
} 
and will make adjustment decisions where needed, especially with a mix of multi-racial, multi-ethnic and multi-cultural students. Questions that come to mind are how best to assist White students, Black students Hispanic students or any other racial group. These questions must be addressed from a multiracial, multicultural collaborative approach. The advantage of promoting a collaborative effort to obtain shared goals is almost a requirement when educating a diverse population (see Table 1).

\section{National Center for Education Statistics}

Table 1

Number of School Principals and Percentage Distribution of School Principals, by Race/Ethnicity, School Type, and Selected School Characteristics: 2007-08

\begin{tabular}{|c|c|c|c|c|c|c|}
\hline & & & & Race/ethnicity & & \\
\hline School type and selected & & Hispanic & & White & Black & \\
\hline & Total number of principals & regardless of race & & non-Hispanic & non-Hispanic & \\
\hline All schools: & 118,610 & 5.9 & & 82.3 & 9.6 & \\
\hline All public schools: & 90,470 & 6.5 & & 80.9 & 10.6 & \\
\hline School classification & & & & & & \\
\hline Traditional public & 86,920 & 6.4 & & 81.5 & 10.2 & \\
\hline Charter school & 3,550 & 9.3 & $!$ & 66.3 & 21.7 & \\
\hline Community type & & & & & & \\
\hline City & 21,560 & 13.4 & & 62.9 & 21.1 & \\
\hline Suburban & 25,880 & 6.9 & & 81.7 & 10.0 & \\
\hline Town & 13,860 & 4.2 & $!$ & 86.7 & 7.2 & \\
\hline Rural & 29,170 & 2.1 & $!$ & 90.6 & 5.1 & \\
\hline School level & & & & & & \\
\hline Elementary & 62,340 & 7.6 & & 79.5 & 10.9 & \\
\hline Secondary & 21,550 & 4.5 & & 84.1 & 9.8 & \\
\hline Combined & 6,580 & 2.8 & $!$ & 83.6 & 10.6 & \\
\hline Student enrollment & & & & & & \\
\hline Less than 100 & 6,950 & 4.8 & $!$ & 83.4 & 9.8 & $!$ \\
\hline 100-199 & 8,520 & 4.0 & $!$ & 87.0 & 7.0 & \\
\hline $200-499$ & 36,830 & 5.4 & & 81.2 & 11.5 & \\
\hline $500-749$ & 20,290 & 8.5 & & 78.3 & 11.2 & \\
\hline \begin{tabular}{|l|}
$750-999$ \\
\end{tabular} & 8,760 & 9.1 & & 79.6 & 9.2 & \\
\hline 1,000 or more & 9,120 & 7.6 & & 79.2 & 11.4 & \\
\hline Percent of K-12 students who & were approved for free or $r$ & educed-price lunche & & & & \\
\hline $0-34$ & 33,980 & 3.3 & & 90.8 & 4.6 & \\
\hline $35-49$ & 14,910 & 2.2 & $!$ & 85.3 & 10.0 & \\
\hline $50-74$ & 19,970 & 7.3 & & 79.0 & 11.2 & \\
\hline 75 or more & 17,700 & 16.0 & & 58.6 & 23.0 & \\
\hline $\begin{array}{l}\text { School did not participate in } \\
\text { free or reduced-price lunch } \\
\text { program }\end{array}$ & 3,910 & 3.4 & $!$ & 88.2 & 6.8 & \\
\hline All BIE schools & 170 & 7.2 & & 36.3 & 2.0 & \\
\hline All private schools: & 27,960 & 4.0 & & 87.3 & 6.5 & \\
\hline
\end{tabular}


The diverse group of teachers in this country includes $84 \%$ whites, $7 \%$ African Americans and $6 \%$ Hispanics. This is just an example of who are teaching our children (see Table 2).

Table 2

Demographic Profile of Teachers in the U.S. Public School Teachers

\begin{tabular}{|c|c|c|c|c|c|}
\hline & 2011 & 2005 & 1996 & 1990 & 1986 \\
\hline $\mathrm{N}=$ & 1,076 & 1,028 & 1,018 & 2,380 & 1,144 \\
\hline \multicolumn{6}{|l|}{$\overline{\text { Age }}$} \\
\hline$\leq 29$ & 21 & 11 & 11 & 15 & 11 \\
\hline $30-39$ & 27 & 22 & 21 & 37 & 36 \\
\hline $40-49$ & 22 & 26 & 44 & 35 & 31 \\
\hline $50+$ & 31 & 42 & 24 & 13 & 22 \\
\hline Gender & $\%$ & $\%$ & $\%$ & $\%$ & $\%$ \\
\hline Male & 16 & 18 & 26 & 29 & 31 \\
\hline Female & 84 & 82 & 74 & 71 & 69 \\
\hline \multicolumn{6}{|l|}{ Race } \\
\hline White & 84 & 85 & 89 & 92 & 91 \\
\hline Black & 7 & 6 & 7 & 5 & 6 \\
\hline Hispanic & 6 & 4 & 2 & 2 & 2 \\
\hline Other & 4 & 5 & 2 & 1 & 0 \\
\hline \multicolumn{6}{|l|}{ Highest Degree Earned } \\
\hline Bachelor's-Education & 29 & 31 & & & \\
\hline Bachelor's-Other & 15 & 11 & & & \\
\hline Master's-Education & 43 & 47 & & & \\
\hline Master's-Other & 12 & 10 & & & \\
\hline Doctorate-Education & 1 & 1 & & & \\
\hline \multicolumn{6}{|l|}{ Years of experience } \\
\hline $1-5$ & 26 & 18 & 12 & 16 & 8 \\
\hline $6-9$ & 16 & 14 & 18 & 18 & 16 \\
\hline $10-14$ & 16 & 16 & 13 & 21 & 24 \\
\hline $15-24$ & 23 & 25 & 37 & 33 & 37 \\
\hline $25+$ & 17 & 27 & 20 & 12 & 15 \\
\hline
\end{tabular}

\section{Profile of Teachers in the U.S. 2011, National Center for Education Information}

Educators who demonstrate commitment to educating all students are those teachers who take teaching very personal and with pride in themselves by trying to meet yearly educational goals. These goals are established to measure individual learning gains demonstrated by students. African American and Hispanic students over time have continued to demonstrate increased mastery scores in the areas of reading and mathematics.

\section{Participatory Teaching and Learning}

Teachers who are aware of student's learning styles could easily involve them in active participation of many lessons. This can be applied in all subject areas where hands-on projects can be included. Problems Based Learning is another example of participatory teaching and learning. This has been recognized as an effective strategy when teaching all student groups and involving them in the lesson to reinforcing critical thinking, higher orders thinking skills, team work and problem solving assignments. A major focus of these projects could be to 
make them culturally sensitive to meet the needs of all participants. This is also an area where students, if given an opportunity could possibly share positive, creative suggestions with buying their in for improvement. They become involved, and sometimes develop a deeper commitment to become a more successful student.

\section{Data Driven Instructions, Planning and Results}

Assessment results of all students are used to show the landscape of the learning acquired during the school year. The data provide educators with hard facts of student mastery skills, learning gains, skill deific areas and a comparative analysis of how students' results match established yearly goals.

Once data have been disseminated for each student, teachers could use the individual student learning gain results to plan lessons for achievement. Each area should have clearly identified dates paired with strategies and benchmarks to reach establish goals for the student, teacher and school. Teachers should also model skill areas to help students better understand what is being requested. They should give examples of skill areas being taught using a variety of teaching strategies; next, students should then be given an opportunity to practice and master the skill before a new assessment is completed. If necessary, students should be given individualized instruction until mastery of skills is accomplished using differentiated techniques to accommodate the student's learning style.

Using data to plan and align instruction is also quite important when planning for student achievement learning gains. It is important that students understand the expectations and encouragement given by teachers to attain mastery of skills.

\section{Accountability: Nation's Report Card}

In an effort to look at the most current and comprehensive assessment data, we selected to include information from the National Assessment of Educational Progress (NAEP) student data results. NAEP is a special project with the National Center for Education Statistics (NCES) and the United States Department of Education, it was established in 1969. While our current focus is on reading and mathematics assessment results, this project also collects data on other academic areas including writing, science, U.S. history, civics and geography. Results from this project are reported on both the state and national levels and policy for this project is set by the National Assessment Governing Board who also oversees the operation.

To keep the public informed about the academic achievement of elementary and secondary students in the United States, The NAEP group created the Nation's Report Card. This provides results of students' assessment in several academic areas. The major focus is on the collection and reporting about student performance and progress on both the state and national levels.

According to NAEP mathematics assessment results for White, Black and Hispanic students included learning gains for each group as documented over twenty-three years, 1990-2013. Analyzing mathematic results, Black students showed the largest gains during the 2011 test results where they demonstrated a $37 \%$ increase. During that same period, both Hispanic and White students demonstrated a 30\% increase. Full details of this research can be found on the NAEP website. Since this research occurred over many years, more results are available for each group identified in the analysis (see Figure 1).

Since the implementation of the initial test results, many states have tried programs that were identified with 
possible skill building areas to help improve overall student academic achievement levels. Many of those programs were considered to be research based and had proven track records of success for students. However, the big question still remains unanswered, how do we close the achievement gap? The answer is still real and have inspired a great deal of research, educational conversations, and other efforts to get to the answer of what do we do to close the achievement gap? Well, should we begin to look critically at other factors such as the individual student and his inner drive to become a successful student, or should we continue to look at what is obvious? What is tradition? How does a successful student look? All of the questions certainly provide us with our own question of, would it make a different? I would say we would certainly have to conduct future research to try to find additional answers to those questions and we might find the magic formula to closing the achievement gap and continuing to provide a bridge to student achievement.

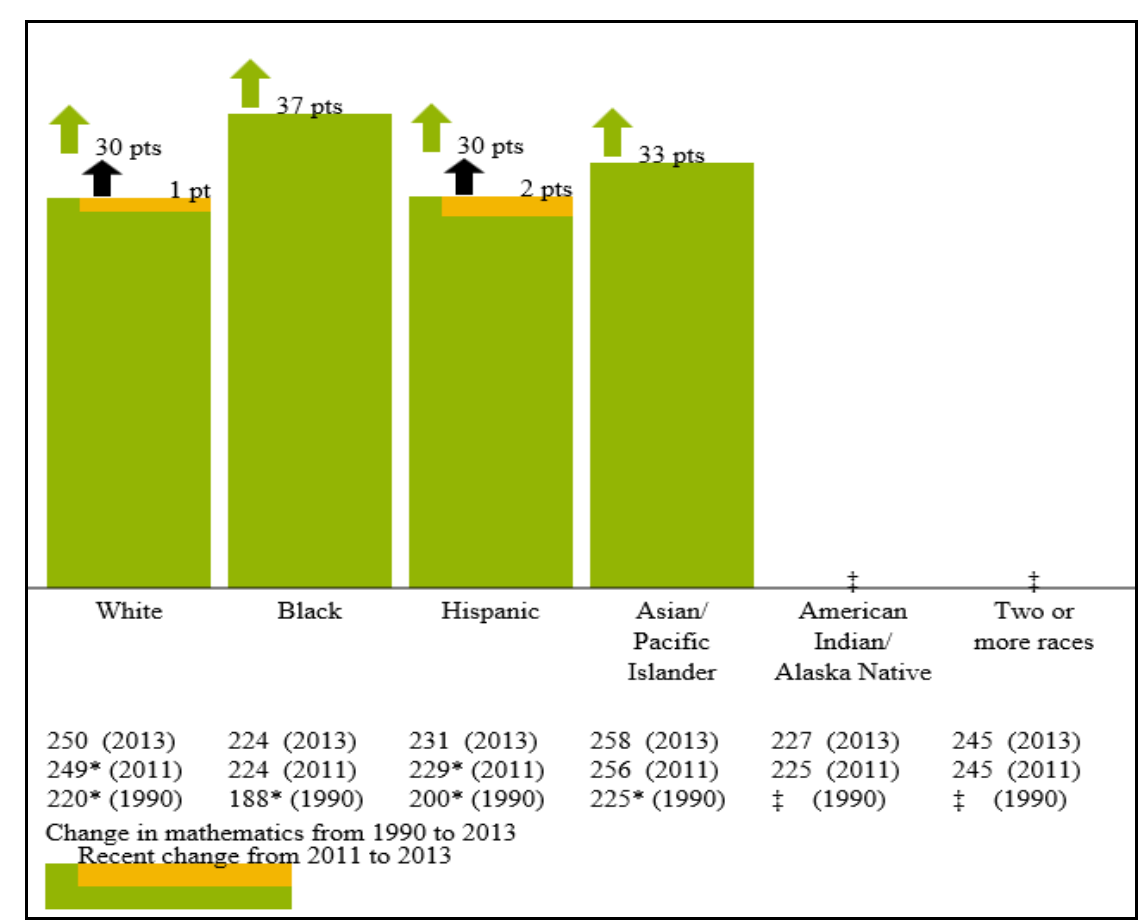

Figure 1. Change in average scores for fourth-grade students assessed in NAEP mathematics, by selected student groups: 1990, 2011, and 2013.

In analyzing the reading results during the same period of time that we looked at the mathematics results we found very different outcomes. Among the three racial groups, Black students demonstrated an increase of $14 \%$, the highest gains in reading over a 23 year period. White students showed an increase of $8 \%$ in reading and Hispanic students showed an increase of $10 \%$ in reading. White students' assessment results were the lowest gains among the three groups, according to the 2013 assessment results. All groups demonstrated a $1 \%$ increase from 2011 to 2013. These reading results were much lower than the gains displayed for the mathematics assessment outcome (see Figure 2).

Even though most test results indicate that there exists a major achievement gap between White, Black and Hispanic students, the reviewed data indicate that the gap is slowly closing among the groups. In Figure 3, analysis showed higher reading scores in 2013 compared to previous years. 


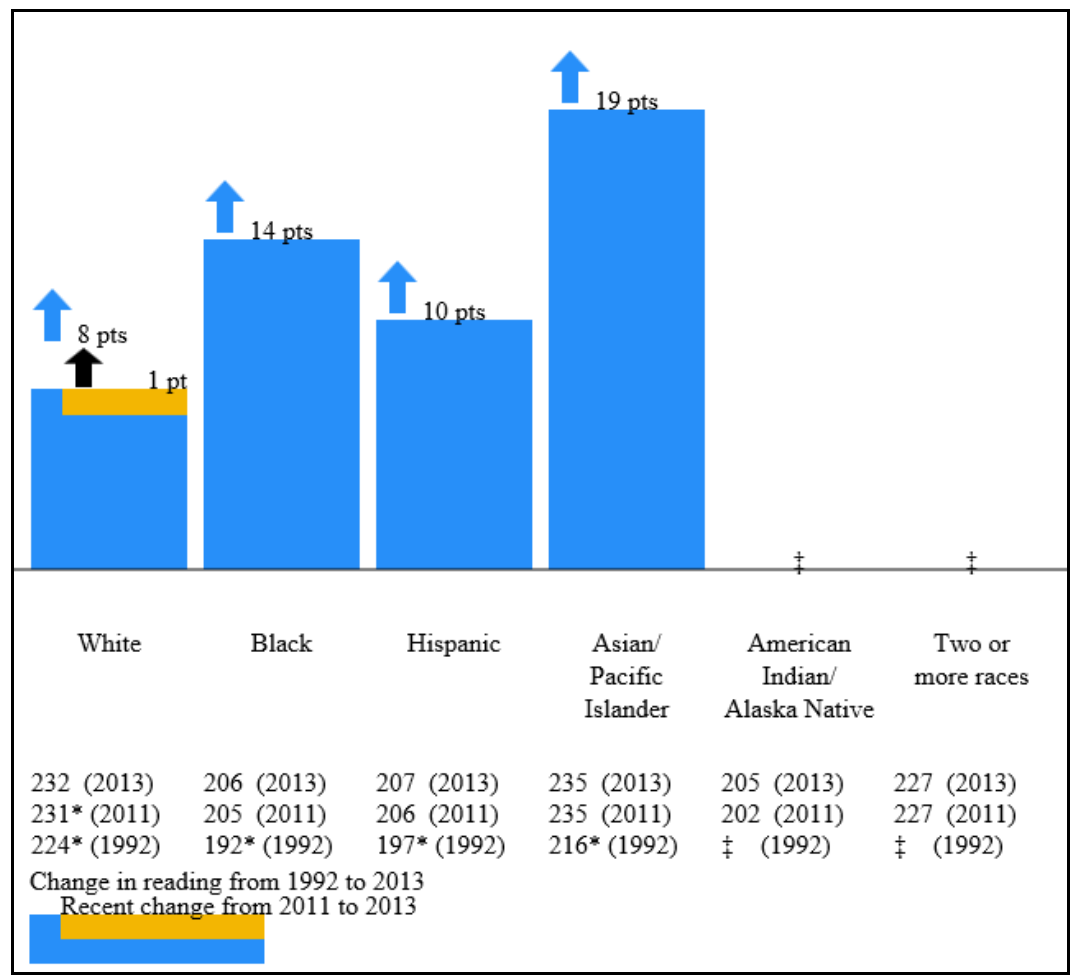

Figure 2. Change in average scores for fourth-grade students assessed in NAEP reading, by selected student groups: 1992, 2011, and 2013.

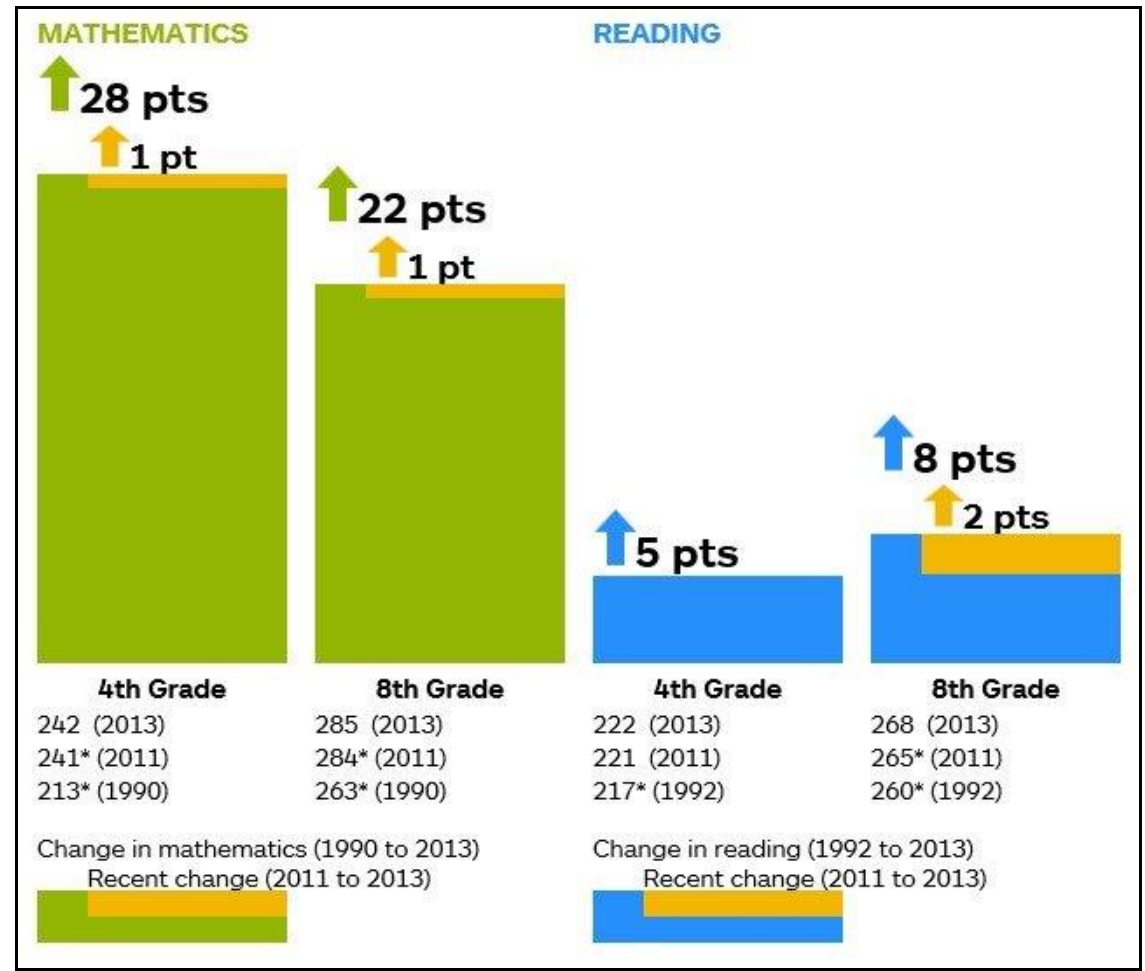

Figure 3. Change in average scores for fourth- and eighth-grade students assessed in NAEP mathematics and reading: Various years, 1990-2013. 


\section{Socioeconomic Status}

Socioeconomic status (SES) influences and impacts all facets of our lives including education. Ray Brogan of the Gale Group indicated that several factors are identified in considering SES which includes income, education, neighborhood, occupation and political power.

Individuals' SES is usually determined by the SES of their family. The SES of the family is calculated based on the measure of the five factors noted above. How well can the family members meet their financial responsibilities? What prestige is associated with the occupation of the head of the household? What level of education have the parents achieved? What is the safety and upkeep of the neighborhood in which the family lives? What hope do the family members reasonably have to influence the government and community policies that affect their lives? A school's SES is determined by the neighborhood in which it is located and by the ESE of the families whose children attend the school.

The support of parents has been synonymous with successful schools, high SES and successful students. Parents work together as partners to enhance the educational experiences of their students by supporting the school, establishing a volunteer program, Parent-Teacher-Student Organizations and fund raising for the school. In schools where there is very little parent involvement, there also appears to be fewer resources provided for these schools that are usually identified as being listed as schools with special needs and low SES. Many of those schools are located in large urban cities such as New York, Washington, DC, Los Angeles, Miami, Chicago and Detroit.

\section{Conclusion}

In conclusion, all students including African American and Hispanic students can and will learn given the opportunity, provide adequate resources, and display commitments from educators to teach all students. Research reminds us that high expectations and positive attitudes inspire students to become more productive with a self-fulfilling prophecy. Many students are empowered to be successful and show confidence that is enhanced by administrators, teachers and parents who set a positive expectation. Students must also be provided with a safe, secure environment conducive to teaching and learning in a culturally diverse, sensitive environment with a multi-ethnic, multi-culture and multi-racial curriculum.

Annual yearly goals should be clearly established with bench marks from realistic standards that are attainable by students. Differentiated instruction and planning should become a part of the on-going instructional process to achieve increased learning gains to meet the needs of all students. Finally, teachers and principals must be involved in improving their skills by participating in professional development on a regular basis. These activities will allow teacher to stay current with cutting edge research based information that could be transferred to the classroom in an effort to improve student achievement.

According to the 2011 and 2012 Test Results, African American and Hispanic students are demonstrating increased progress towards closing the achievement gap between White, African American and Hispanic students. The commitment to continue educating students is vital to the future success of promoting multiculturalism in the United States and the world as we continue to evolve in this ever changing global society. 


\section{Recommendations}

Recommended Strategies that could be implemented to help bridge the achievement gap for students are listed below:

(1) Increase time on learning skills;

(2) Extended school day;

(3) More individualized instructions;

(4) Provide additional opportunities for student to practice new skills;

(5) Practice additional higher order thinking activities;

(6) Plan collaborative problem based learning activities;

(7) Encourage and plan critical thinking skill projects;

(8) Allow time for students to verbalized summarizing, sequencing, making inferences and making projections;

(9) Model example of oral presentations emphasizing the problem solving process;

(10) Plan embedded daily writing assignments to enhance various types of writing skills and encourage creative writing and oral story telling.

\section{References}

Aikens, N., \& Barbarin, O. (2008). Education \& Socioeconomic Status. Retrieved from http://www.apa.org/about/gr/pi.org The NCES Publication and Products, United States Department of Education, P.O. Box 22207, Alexandria, Virginia. Retrieved from http://nces.edgov/pubsearch

Brogan, R. (2006-2012). Socioeconomic Status, Education.com. $\quad$ Retrieved from http://www.education.com/print/socioeconomic-status.com

Colvin, R. L., Darling-Hammond, L., DeVita, M. C., \& Haycock, K. (October, 2007). A bridge to school reform. In Wallace Foundation's National Conference. Retrieved from http://www.wallacefoundation.org

Walker, D. F. (2015). Low income vs. high income students \& education. Demand Media. Retrieved from http://www.globalpost.com 